\title{
Study on uptake of PLA-Pluronic P85-PLA nanoparticles with Caco-2 cells
}

\section{SHU Cheng Chuang ${ }^{a}$, HUANG Han ${ }^{b}$, YAO Lihua ${ }^{c}$, SUN Li Zhen ${ }^{d}$, XIONG Xiang Yuan ${ }^{\mathrm{e}}$ and LI Yu Ping ${ }^{\mathrm{f}_{*}}$}

\author{
School of life science, Jiangxi Science \& Technology Normal University, Nanchang, 330013, \\ Jiangxi, China \\ alshuchengchuang@126.com, bhuanghan018@163.com, '278547110@qq.com, \\ dsunlz1111@gmail.com, exyxiong@gmail.com, ${ }^{f_{*}}$ pingyuli2013@163.com
}

Keywords: PLA-Pluronic P85-PLA; nanoparticle; insulin; Caco-2 cell; uptake

Abstract. We have shown that insulin-loaded Poly(lactic acid)-b-Pluronic-b-poly(lactic acid) nanoparticles (PLA-P85-PLA-NPs) had the hypoglycemic effect after oral administration on diabetic mice. In the present work, free insulin (INS) as controls, the influence of some factors such as time, temperature, $\mathrm{pH}$ level, and INS concentration on the uptake efficacy of PLA-P85-PLA-NPs as drug carriers were investigated through a Caco-2 cells. The micrographs of Caco-2 cell model were observed by microscopy. The cytotoxicity of PLA-P85-PLA-NPs in vitro was evaluated by MTT assay. The insulin concentrations in Caco-2 cells were determined by high-performance liquid chromatography (HPLC). Compared with INS groups, PLA-P85-PLA-NPs uptake was not controlled by $\mathrm{pH}$ levels. PLA-P85-PLA-NPs can be uptake by Caco-2 cells, and the absorption of PLA-P85-PLA-NPs is dependent on the concentration and incubation time. INS-loaded PLA-P85-PLA-NPs significantly enhanced insulin absorption. These results suggest that PLA-P85-PLA-NPs were more efficient than individual drugs into Caco-2 cells in a short period of time, and PLA-P85-PLA-NPs might be a useful drug carrier for proteins and peptides.

\section{Introduction}

Oral administration is considered to be the most convenient route of administration for therapeutic agents, especially when long-term or daily use is required. However, oral administration of protein drugs, e.g. Insulin (INS) is poorly absorbed because of their susceptibility to enzymatic degradation and their low permeability across the intestinal epithelium [1]. Being conscious of these important biopharmaceutical limitations, many researchers have attempted to design new carrier delivery system intended to protect INS from the gastrointestinal (GI) environment since its discovery in 1922.

Among them, the encapsulation of macromolecular drugs in nanoparticles (NPs) is considered a promising approach toward overcoming the mentioned barriers. Pluronics consisting of poly (ethylene oxide)-poly (propylene oxide)-poly (ethylene oxide) (PEO-PPO-PEO) can assemble into micelles, with the PPO blocks forming a hydrophobic core and the PEO blocks the surrounding hydrophilic corona in solution [2]. Several PEO-PPO-PEO block copolymers are widely used for several routes of administration for drug delivery, and have been reported to be a promising way to improve the oral bioavailability of peptides and proteins [2, 3].

In recent years, we have particularly focused our work on designing and evaluating a novel nanoparticles (NPs) delivery system that is able to provide protection from the GI environment and enhance absorption of INS in the intestinal epithelium. The NPs delivery system is composed of poly (lactic acid) (PLA) and Pluronic 85 block copolymers (PEO-PPO-PEO) prepared by a simple and mild ionic-gelation method. More specifically, we have observed that PLA-P85-PLA-NPs are able to enhance and prolong the systemic absorption of the model drugs, administered orally [4]. However, the drug absorption in humans and absorption characteristics did not cleared. Thus, the aim of the present work was to investigate the theoretical basis for the understanding of the uptake of PLA-P85-PLA-NPs as carriers for the oral administration of insulin with the human Caco-2, a continuous line of heterogeneous human epithelial colorectal adenocarcinoma cells. The effects of INS 
concentration, treated time, $\mathrm{pH}$, and temperature of incubation on the uptake of PLA-P85-PLA-NPs were investigated in vitro. The present study could provide a theoretical reference for the formulation and development of a rational design of new agents, as well as for the selection of its administration route.

\section{Materials and Methods}

Materials. The polymeric NPs comprising of commercial Pluronic P85 (PEO-PPO-PEO) and biodegradable poly(lactic acid)(PLA) have been prepared in our laboratory. Human insulin (Novolin R, $100 \mathrm{IU} / \mathrm{ml}$ ) was purchased from Novo Nordisk A/S (Bagsvaerd, Denmark). The human colon adenocarcinoma cell line, Caco-2, was obtained from the American Type Culture Collection (Rockville, USA). 3-[4,5-dimethylthiazol-2-yl]-2,5-diphenyltetrazolium bromide thiazolyl blue (MTT), Dulbecco's modified Eagle's medium (DMEM) and fetal bovine serum (FBS) were purchased from Gibco BRL (Grand Island, USA). Hank's balanced salt solution (HBSS), and Micro BCA protein assay kit were provided by Beyotime Institute of Biotechnology (Jiangsu, China). All other chemicals used were of analytical grade.

Preparation of nanoparticles. The blank PLA-Pluronic P85-PLA-NPs and INS-loaded PLA-Pluronic P85-PLA-NPs were prepared as previously described with some minor modifications [5]. Briefly, appropriate amounts of Pluronic/PLA block copolymers were dissolved in THF, and the polymer solution was added drop-wise to ultra pure water or INS solution under gentle stirring. Then, the polymer solution was dialyzed using a cellulose membrane dialysis tubing (molecular weight cut-off 8000-14000 Da) to remove THF and free INS from the solution. The ultra pure water was exchanged at intervals of $1 \mathrm{~h}$. The dialysed solution was then analysed. The morphologic characteristics of blank and INS-loaded NPs were observed by dynamic light scattering (DLS) techniques (PSS NICOMP 380, USA).

Cell culture. Caco-2 cells were grown in tissue culture flasks and cultured under previously described conditions [6]. At about $80 \%-90 \%$ confluence, these cells were seeded approximately at $5 \times 10^{4}-2.5 \times 10^{5}$ cells $/ \mathrm{mL}$ for all further studies.

Cytotoxicity studies. The cytotoxicity of PLA-P85-PLA-NPs in vitro was evaluated by micrographs and MTT assay [6]. Briefly, Caco-2 cells $\left(5 \times 10^{4}\right.$ cells $\left./ \mathrm{mL}\right)$ were seeded in 96-well microtiter plates and cultured for over $24 \mathrm{~h}$. After $24 \mathrm{~h}$, the cells were washed with PBS and replaced with medium containing INS, PLA-P85-PLA-NPs, and INS-loaded PLA-P85-PLA-NPs at different concentrations $(5,10,20$, and $50 \mathrm{mg} / \mathrm{L})$. Cells were incubated for additional $24 \mathrm{~h}$, followed by washing with PBS. Micromorphology of Caco-2 cells was observed by light microscopy. The cell viability was measured by MTT assay. The absorbance was measured at $492 \mathrm{~nm}$ using a microplate reader (Multiscan Mk3

, USA Thermo Labsystems). The reading taken from the wells containing cells cultured with control medium was considered as $100 \%$ viability. The cell viable rate was calculated by the following equation: viable rate $(\%)=($ ODsample/ODcontrol $) \times 100 \%$.

Uptake studies in Caco-2 cells. Cell uptake studies were performed with cell monolyers according to the method described by Guan M. et al [7]. Caco-2 cells were seeded on 24-well tissue culture plates (Corning, Corning, NY) at a density of $1 \times 10^{4}$ cells $/ \mathrm{mL}$. The cell monolayers were used on the 15 th day for uptake experiments. The Caco- 2 cell monolayers were washed twice with the pre-warmed HBSS ( $\mathrm{pH} 7.4$ ), and then pre-incubated with $1 \mathrm{ml}$ of the incubation medium for $15 \mathrm{~min}$ at $37^{\circ} \mathrm{C}$. The medium was then removed after the pre-incubation period and uptake was initiated at $4^{\circ} \mathrm{C}$ or $37^{\circ} \mathrm{C}$ by adding $1 \mathrm{ml}$ of HBSS (pH 6.0, 7.4) containing different concentration $(5,10,20,50 \mathrm{mg} / \mathrm{L})$ of INS or INS-loaded PLA-P85-PLA-NPs. At various time points $(0.5 \mathrm{~h}, 1 \mathrm{~h}, 2 \mathrm{~h}, 4 \mathrm{~h})$, the cells were quickly washed three times with cold HBSS, and then collected with a cell scraper (Corning). Next, the cells were homogenated, vortexed, and centrifuged at 12,000 rpm for $15 \mathrm{~min}$. The supernate was sampled, and a $20 \mu \mathrm{L}$ aliquot of the supernatant was used for HPLC analysis. Protein content was determined via 
bicinchoninic acid (BCA, Pierce) assay according to the manufacture's protocol. All text, figures and tables must be in English.

Statistical analysis. The statistical analysis of the samples was performed using a Student's $t$-test. All of the data were represented as mean \pm standard deviation (SD) for at least three independent samples. $P<0.05$ was considered statistically significant.

\section{Results and discussion}

Size of PLA-P85-PLA-NPs. Ideal nano-complexes with or without insulin should be the particle sizes $<500 \mathrm{~nm}$ to facilitate epithelial uptake. PLA-Pluronic-PLA block copolymers were synthesized previously by our group. In this study, PLA-P85-PLA (Mn 10200, PLA $55 \mathrm{wt} \%$ ) were used. The average diameters of nanoparticles were determined by DLS. The size for the vesicle is $165.1 \pm 6.52$ $\mathrm{nm}$ for PLA-P85-PLA. The INS-loaded NPs showed average particle sizes are $240.2 \pm 10.43 \mathrm{~nm}$. A significant size increase was observed in the presence of INS-loaded. These results indicated that PLA-P85-PLA-NPs are expected to have potential applications as drug delivery systems.

Cytotoxicity studies of PLA-P85-PLA-NPs in Caco-2 cells. Viability assays are basic steps in toxicology that explain the cellular response to a toxicant. Also, they give information on the cell's death, survival, and metabolic activities. In order to investigate the cytotoxicity of PLA-P85-PLA-NPs on cell proliferation of Caco-2, the cells were cultured for $24 \mathrm{~h}$ in media containing INS, PLA-P85-PLA-NPs, and INS-loaded PLA-P85-PLA-NPs $(10,50 \mathrm{mg} / \mathrm{L})$. As shown in figure 1, compared with the control group, treatment with PLA-P85-PLA-NPs did not induce significant micromorphology changes of Caco-2 cell. But, the cell density was significantly higher in cells treated with INS and INS-loaded PLA-P85-PLA-NPs (10, $50 \mathrm{mg} / \mathrm{L})$.

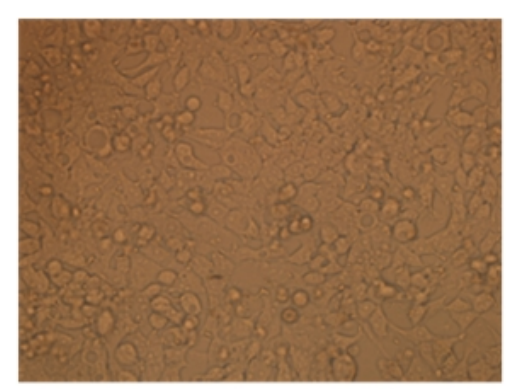

Control (Caco-2 cell)

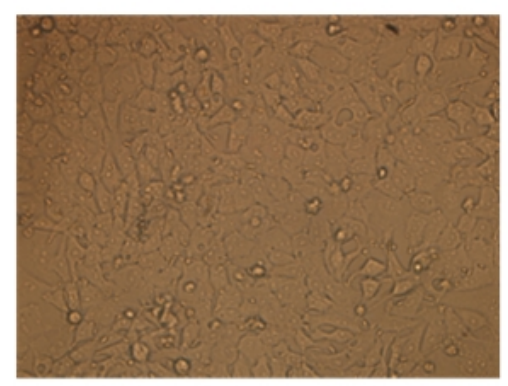

PLA-P85-PLA NPS

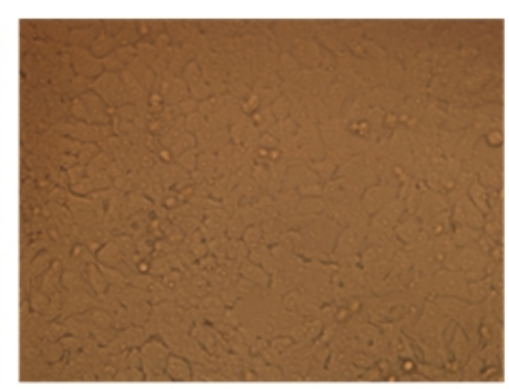

$10 \mathrm{mg} / \mathrm{L}$ Insulin

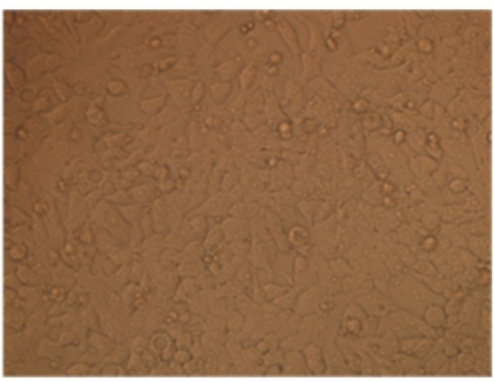

$10 \mathrm{mg} / \mathrm{L}$ Insulin-loaded PLA-P85-PLA NPs $50 \mathrm{mg} / \mathrm{L}$ Insulin-loaded PLA-P85-PLA NPs

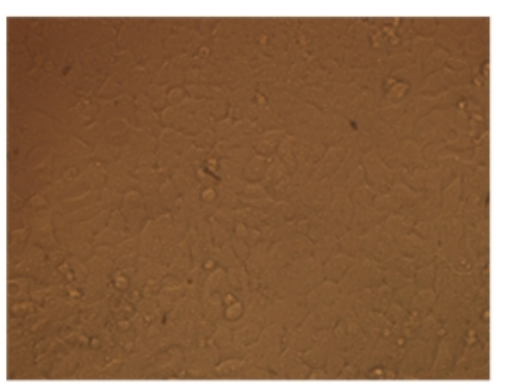

$50 \mathrm{mg} / \mathrm{L}$ Insulin

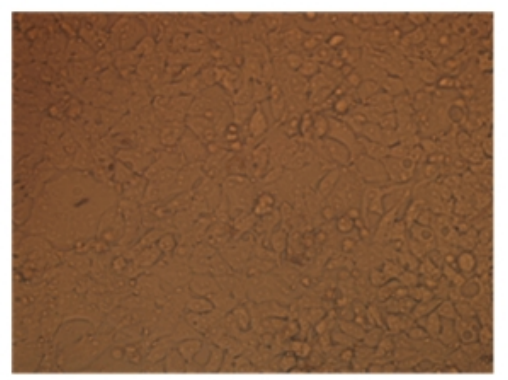

Fig. 1. Micromorphology of Caco-2 cells were cultured with INS, PLA-P85-PLA-NPs, and INS-loaded PLA-P85-PLA-NPs for $24 \mathrm{~h}(\times 200)$

The number of viable cells was assessed by MTT assay. As shown in figure 2, treatment with INS, PLA-P85-PLA-NPs, and INS-loaded PLA-P85-PLA-NPs $(5,10,20,50 \mathrm{mg} / \mathrm{L})$ at $37^{\circ} \mathrm{C}$ for $24 \mathrm{~h}$ did not induce significant cytotoxicity to the Caco-2 cell. In contrast, exposure to $5-50 \mathrm{mg} / \mathrm{L}$ INS and INS-loaded PLA-P85-PLA-NPs caused a significant increase in the viability of Caco-2 cells $(\mathrm{P}<0.001)$. Both free INS and INS-loaded PLA-P85-PLA-NPs at the different concentration showed almost the same biological effect on the increase in cellular metabolic activity stimulated by INS. The 
results showed that PLA-P85-PLA-NPs have a very good biocompatibility with the monolayers. The results obtained were in good agreement with the literature $[5,6]$.

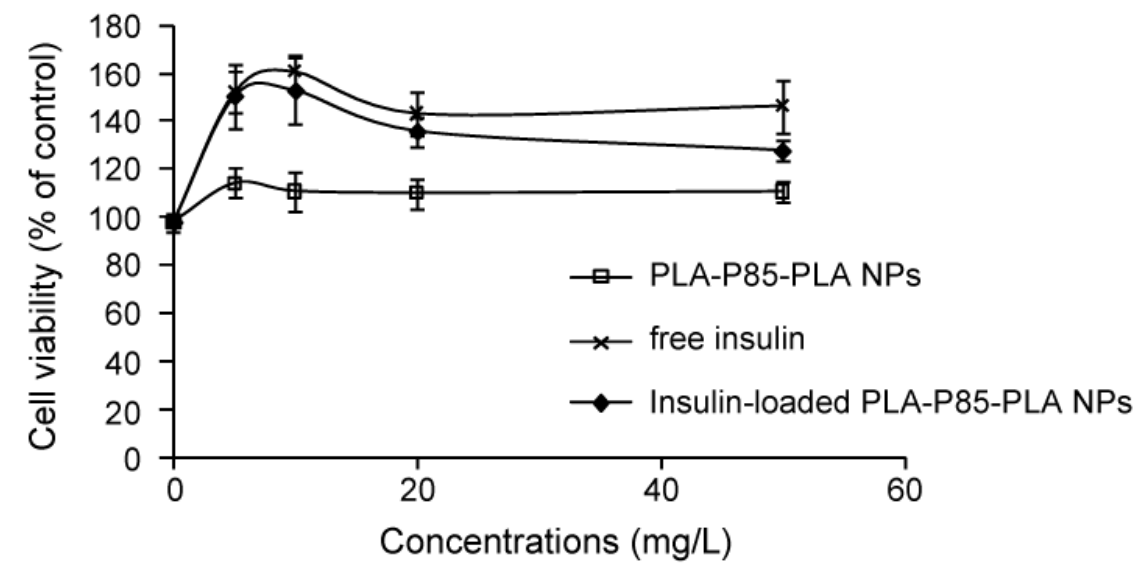

Fig. 2. Cytotoxicity of PLA-P85-PLA NPs affects cell viability using the MTT assay. Caco-2 cells were treated with different concentrations of PLA-P85-PLA NPs, INS and INS-loaded PLA-P85-PLA NPs for $24 \mathrm{~h}$. Results are expressed as the percent of cell activity compared to the control. Data represent the means \pm S.D. of triplicate experiments.

\section{Uptake of PLA-P85-PLA-NPs into Caco-2 monolayers.}

Effect of pH on uptake. The uptake rate of INS and INS-loaded PLA-P85-PLA-NPs $(20 \mathrm{mg} / \mathrm{L})$ into Caco-2 monolayers in pH 6.0 were $(26.4 \pm 1.41)$ and $(43.6 \pm 3.04) \%$, respectively. The uptake rate of INS and INS-loaded PLA-P85-PLA-NPs $(20 \mathrm{mg} / \mathrm{L})$ into Caco-2 monolayers in $\mathrm{pH} 7.4$ were $(30.7 \pm 2.91)$ and $(46.4 \pm 1.44) \%$, respectively. The results showed that PLA-P85-PLA-NPs can increase the uptake of Caco-2 cells, but no significant differences between the uptake rate in the two $\mathrm{pH}$ values $(\mathrm{P}>0.05)$ (Fig. 3). Hence, the subsequent experiments were performed using the medium at $\mathrm{pH} 7.4$.
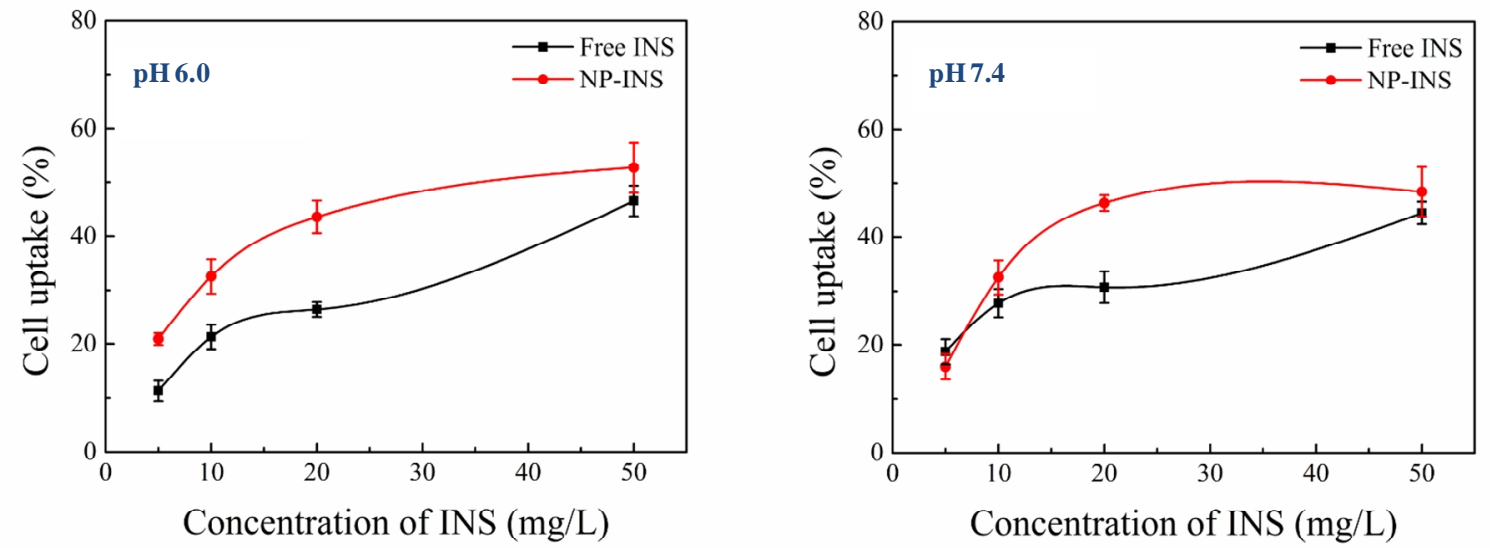

Fig.3 Effect of $\mathrm{pH}$ on Caco-2 cells uptake. Error bars represent standard error of the mean value for three determinations.

Effect of temperature on uptake. The uptake rate of insulin and insulin-loaded PLA-P85-PLA-NPs $(20 \mathrm{mg} / \mathrm{L})$ into Caco-2 monolayers in $4^{\circ} \mathrm{C}$ were $(25.6 \pm 2.46)$ and $(36.4 \pm 1.18) \%$, respectively. The uptake rate of insulin and insulin-loaded PLA-P85-PLA-NPs $(20 \mathrm{mg} / \mathrm{L})$ into Caco-2 monolayers in $37^{\circ} \mathrm{C}$ were $(26.8 \pm 1.35)$ and $(30.8 \pm 1.02) \%$, respectively. The results showed that PLA-P85-PLA-NPs can increase the uptake of Caco-2 cells, but no significant differences between the uptake rate in the two temperature $(\mathrm{P}>0.05)$ (Fig. 4). 


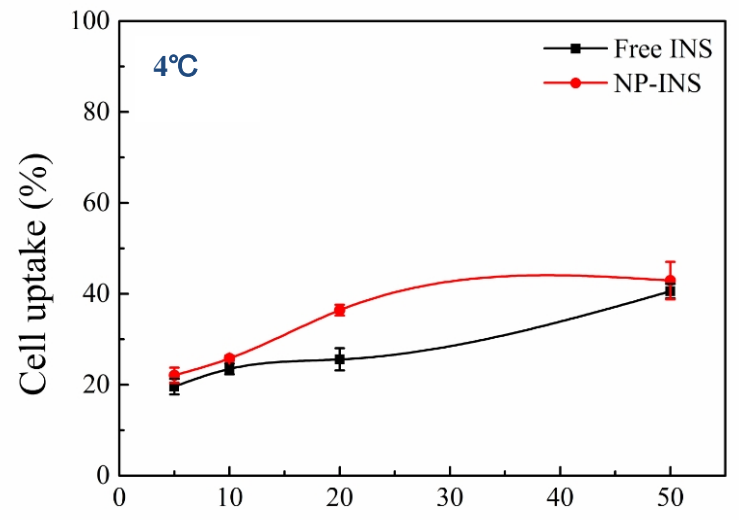

Concentration of INS $(\mathrm{mg} / \mathrm{L})$

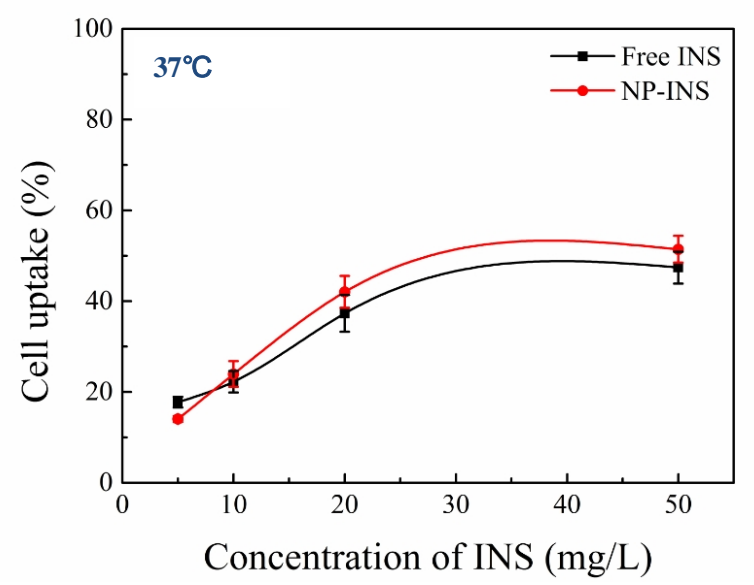

Fig. 4 Effect of temperature on Caco-2 cells uptake. Error bars represent standard error of the mean value for three determinations.

Effect of time and concentration on the uptake. The uptake of INS and INS-loaded PLA-P85-PLA-NPs into Caco-2 monolayers was shown to be linear in relation to time, from $0.5 \mathrm{~h}$ to 2 $\mathrm{h}$ at $37^{\circ} \mathrm{C}$. Concentration dependence was observed for the uptake of INS-loaded PLA-P85-PLA-NPs in the concentration range of $5 \mathrm{mg} / \mathrm{L}$ to $50 \mathrm{mg} / \mathrm{L}$ (Fig. 5).
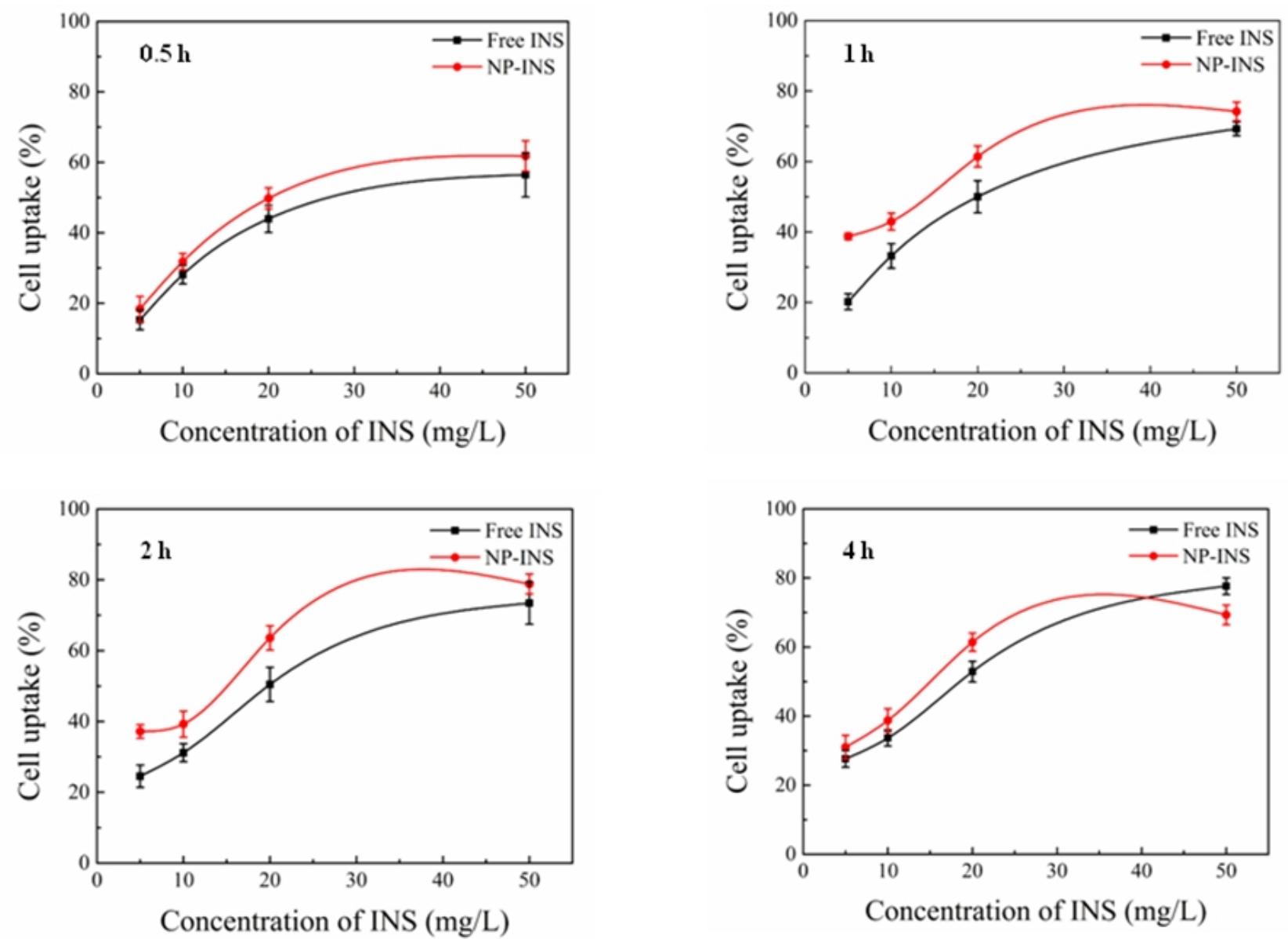

Fig.5 Effect of time and concentration on the uptake in Caco-2 cell monolayers. Error bars represent standard error of the mean value for three determinations. 


\section{Conclusions}

In this paper we present the uptake characteristics of PLA-P85-PLA-NPs, a new drug nano-carrier for the oral administration of proteins. The PLA-P85-PLA-NPs resulted in an increase of the insulin uptake of the Caco-2 cells. The uptake was not controlled by $\mathrm{pH}$ levels, but were positively correlated to uptake concentration and time. Moreover, these new NPs performed a very good efficiency at increasing the intestinal absorption of the model proteins. PLA-P85-PLA-NPs might be a useful drug carrier for proteins and peptides.

\section{Acknowledgements}

This work was financially supported by the common program of the National Natural Science Foundation of China (Grant No. 81060264, No. 31360376, No.21264009), the Natural Science Foundation of Jiangxi Province of China (Grant No. 20132BAB205091), and the Science and Technology Program of Department of Education of Jiangxi Province (Grant No. GJJ13579).

\section{References}

[1] M.A. Lopes, B.A. Abrahim, R. Seoca, et al. Intestinal uptake of insulin nanoparticles: facts or myths? Curr. Pharm. Biotechnol. 15(2014)629-638.

[2] E.V. Batrakova, A.V. Kabanov. Pluronic block copolymers: evolution of drug delivery concept from inert nanocarriers to biological response modifiers, J. Control Rel. 130(2008)98-106.

[3] Y.Y. Luo, X.Y. Xiong, Y. Tian, et al. A review of biodegradable polymeric systems for oral insulin delivery, Drug. Deliv. 11(2015)1-10.

[4] X.Y. Xiong, Y.P. Li, Z. L. Li, et al. Vesicles from Pluronic/poly(lactic acid) block copolymers as new carriers for oral insulin delivery, J. Control Rel.120(2007)11-17.

[5] Y.P. Li, L.Z. Sun, L.H. Yao, et al. Acute and subacute toxicity studies of Pluronic P85/poly(lactic acid) nanoparticles in mice, Micro. \& Nano. Letters. 8(2013)796-800.

[6] L.Z. Sun, Y.P. Li, W.Z. Qiu, et al. Cytocompatibility evaluation of PLA-P85-PLA nanoparticles in vitro, Funct. Mater.; 44(2013)3135-3138, 3142.

[7] M. Guan, Q.L. Zhu, Y. Liu, et al. Uptake and transport of a novel anticancer drugdelivery system: lactosyl-norcantharidin-associated N-trimethyl chitosan nanoparticles across intestinal Caco-2 cell monolayers, Int. J. Nanomed.7(2012)1921-1930. 